\title{
RESPOSTA FISIOLÓGICA E PERCEPTUAL NA VELOCIDADE CRÍTICA E PONTO DE COMPENSAÇÃO RESPIRATÓRIA
}

\author{
PHYSIOLOGICAL AND PERCEPTUAL RESPONSEAT CRITICAL SPEED AND RESPIRATORY \\ COMPENSATION POINT
}

Artigo Original

OrIGINAL ARTICLE

Artículo Original

\author{
RESPUESTA FISIOLÓGICA Y PERCEPTUAL EN LA VELOCIDAD CRÍTICA Y PUNTO \\ DECOMPENSACIÓN RESPIRATORIA
}

\begin{abstract}
Danilo Alexandre Massini (Educador Físico)

Dalton Muller Pessôa Filho' (Educador Físico)

Renato Aparecido Corrêa Caritá (Educador Físico)

Benedito Sérgio Denadai ${ }^{2}$

(Educador Físico)

1. Faculdade de Ciências, Universidade Estadual Paulista "Júlio de Mesquita Filho" (UNESP), Bauru, São Paulo, Brasil.

2. Laboratório de Performance Humana, Universidade Estadual Paulista "Júlio de Mesquita Filho" (UNESP), Rio Claro, São Paulo, Brasil.
\end{abstract}

\section{Correspondência:}

Dalton Muller Pessôa Filho. Departamento de Educação Física, Faculdade de Ciências, Universidade Estadual Paulista "Júlio de Mesquita Filho" (UNESP). Av. Eng. Luiz Edmundo Carrijo Coube, 1401 Vargem Limpa, Bauru, SP, Brasil. 17033-360 dmpf@fc.unesp.br

\section{RESUMO}

Introdução: O ponto de compensação respiratória (PCR) representa a taxa metabólica durante um teste incremental máximo, a partir da qual se perde o controle do equilíbrio ácido-base. Entretanto, a velocidade crítica (VC) define o limite superior do domínio pesado do exercício, no qual a exaustão não está relacionada à perturbação metabólica. Objetivo: Comparar a resposta fisiológica (frequência cardíaca - FC, lactato sanguíneo - [La] e consumo de oxigênio - $\dot{\mathrm{VO}}_{2}$ ) e perceptual (percepção subjetiva de esforço - PSE) durante o exercício na VC e no PCR, visando analisar as similaridades contextuais. Métodos: Dez corredores adolescentes (15,8 $\pm 1,7$ anos)

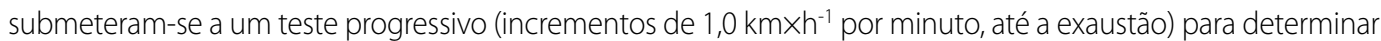
$\dot{V} \mathrm{O}_{2 \text { max }}$ PCR e velocidades correspondentes. A VC foi estimada por três esforços, com tempo limite previsto entre 2 e 12 minutos. Os participantes realizaram dois esforços de sete minutos cada, em dias diferentes, na VC e vPCR. Foram registradas FC, PSE (escala 6-20) a cada minuto e [La] de repouso e após cada esforço. O $\mathrm{V}_{2}$ foi analisado respiração a respiração durante os esforços. O teste de Mann-Whitney comparou as respostas de $\mathrm{FC}$, [La], $\mathrm{V}_{2} \mathrm{e}$ PSE em VC e vPCR. A variância entre essas respostas foi analisada pelo coeficiente de dispersão $\left(R^{2}\right)$. O índice de significância foi $P \leq 0,05$. Resultados: Os valores máximos no teste progressivo foram $56,1 \pm 5,5 \mathrm{ml} \times \mathrm{kg}^{-1} \times \mathrm{min}^{-1}\left(\dot{\mathrm{V}}_{2 \mathrm{max}}\right)$, $16,5 \pm 1,7 \mathrm{~km} \times h^{-1}\left(\mathrm{VVO}_{2 \max }\right), 202 \pm 12 \mathrm{bpm}\left(\mathrm{FC}_{\max }\right), 19,4 \pm 1,3$ (PSE) e 12,7 $\pm 3,1 \mathrm{mmolxL}^{-1}$ ([La]). Não foram observadas

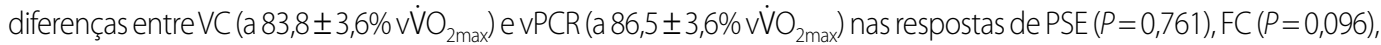
[La] $(P=0,104)$ e $\dot{V O}_{2}(P=0,364)$. Demonstrou-se haver correlações entre VC e vPCR nas respostas de [La] $\left(R^{2}=0,76\right.$; $P=0,011)$, PSE $\left(R^{2}=0,84 ; P<0,01\right)$ e $\dot{V}_{2 \max }\left(R^{2}=0,82 ; P<0,01\right)$. Conclusão: Pode-se inferir que o exercício em $P C R$ reproduziu uma resposta fisiológica e perceptual similar àquela em $\mathrm{VC}$.

Descritores: consumo de oxigênio; frequência cardíaca; ácido láctico; exercício.

\section{ABSTRACT}

Introduction: The respiratory compensation point (RCP) is the metabolic rate for a maximal incremental test, from which the control of the acid-base balance is lost. However, the critical velocity (CV) defines the upper limit of the heavy exercise domain, in which the exhaustion is not related to metabolic disturbance. Objective: To compare the physiological (heart rate- $\mathrm{HR}$, blood lactate - [La], and oxygen uptake- $\mathrm{V}_{2}$ ) and perceptual (rating of perceived exertion-RPE) responses, while exercising at $C V$ and at $R C P$, in order to analyze contextual similarities. Methods: Ten adolescent runners (15.8 \pm 1.7 years old) underwent progressive test (increments of $1.0 \mathrm{~km} \times h^{-1}$ per minute until exhaustion) to determine $\dot{V}_{2 \max } R C P$ and the correspondent velocities. The $C V$ was estimated for three efforts with time limit of 2 to 12 minutes. The participants performed two efforts of seven minutes each on separate days, in CV and VRCP HR, RPE (scale 6-20) were recorded every minute, and [La] was measured at rest and after each effort. The $\mathrm{V}_{2}$, was analyzed breath by breath during efforts. The Mann-Whitney test compared $\mathrm{HR}$, [La], $\mathrm{VO}_{2}$, and RPE responses in $\mathrm{CV}$ and $V R C P$. The variance between these responses was examined by the scatter coefficient $\left(R^{2}\right)$. The significance level was $P \leq 0.05$. Results: The maximum values in the progressive test were $56.1 \pm 5.5 \mathrm{~m} / \times \mathrm{kg}^{-1} \times \mathrm{min}^{-1}\left(\dot{V O}_{2 \text { max }}\right), 16.5 \pm 1.7{\mathrm{~km} \times h^{-1}}^{-1}\left(\dot{V O}_{2 \text { max }}, 202 \pm 12 \mathrm{bpm}\left(H R_{\text {max }}\right), 19.4 \pm 1.3\right.$ (RPE) and $12.7 \pm 3.1 \mathrm{mmol}^{-1}$ ([La]). No differences were observed between $C V\left(a t 83.8 \pm 3.6 \% \vee \dot{V}_{2 \max }\right)$ and $v R C P\left(a t 86.5 \pm 3.6 \% \vee v \mathrm{VO}_{2 \max }\right)$ in RPE responses $(P=0.761), H R(P=0.096),[L a](P=0.104)$ and $\dot{V O}_{2}(P=0.364)$ responses. Correlations were observed between the $C V$ and $V R C P$ in $[L a]\left(R^{2}=0.76 ; P=0.011\right), R P E\left(R^{2}=0.84 ; P<0.01\right)$ and $\dot{V}_{2 \max }\left(R^{2}=0.82 ; P<0.01\right)$ responses. Conclusion: It was inferred that exercise in $R C P$ reproduced a physiological and perceptual response similar to that in $C V$.

Keywords: oxygen consumption; heart rate; lactic acid; exercise.

\section{RESUMEN}

Introducción: El punto de compensación respiratoria (PCR) es la tasa metabólica para un test incremental máximo, a partir de la cual se pierde el equilibrio ácido-base. Sin embargo, la velocidad crítica (VC) define el límite superior del dominio de ejercicio pesado, en el que el agotamiento no está relacionado con el trastorno metabólico. Objetivo: Comparar la respuesta fisiológica (frecuencia cardiaca - $F C_{1}$ lactato en sangre - [La] y consumo de oxígeno - $\dot{V}_{2}$ ) y la perceptual (percepción subjetiva del esfuerzo - PSE) en VCy PCR con el fin de analizar las similitudes contextuales. Métodos: Diez corredores adolescentes (15,8 $\pm 1,7$ años) fueron sometidos a una prueba progresiva (incrementos de 1,0 $\mathrm{km} \times \mathrm{h}^{-1} \mathrm{por}$ 
minuto hasta el agotamiento) para determinar $\mathrm{V}_{2 \max }$ PCRy las velocidades correspondientes. La VC se estimó por tres esfuerzos con tiempo límite previsto entre 2 y 12 minutos. Los participantes realizaron dos esfuerzos de siete minutos cada en diferentes dias en VC y VPCR. Se registraron, FC, PSE (escala 6-20) cada minuto y [La] de reposo y después de cada esfuerzo. El $\dot{V}_{2}$ se analizó respiración a respiración durante el esfuerzo. La prueba de Mann-Whitney comparó las respuestas de FC, [La], V $\mathrm{O}_{2}$ y PSE en VC y VPCR. La varianza entre estas respuestas fue examinada por el coeficiente de dispersión ( $\left.R^{2}\right)$. El nivel de significación fue de $P \leq 0,05$. Resultados: Los valores máximos en la prueba progresiva fueron

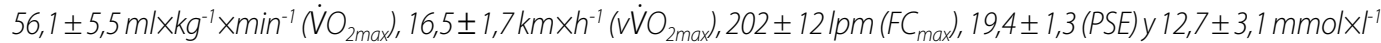
([La]). No se observaron diferencias entre $V C\left(\right.$ en $\left.83,8 \pm 3,6 \% \vee V \dot{V} O_{2 \max }\right)$ y $\vee P C R\left(\right.$ en $86,5 \pm 3,6 \% \vee \dot{V} O_{2 \text { max }}$ ), en las respuestas de PSE $(P=0,761), F C(P=0,096)$, $[L a](P=0,104)$ y $\dot{V O}_{2}(P=0,364)$. Se ha demostrado que hay correlaciones entre CVy $v P C R$ en las respuestas del $[L a]\left(R^{2}=0,76, P=0,011\right)$, PSE $\left(R^{2}=0,84, P<0,01\right)$ y del $\dot{V}_{2 \max }\left(R^{2}=0,82 ; P<0,01\right)$. Conclusión: Se puede deducir que el ejercicio en $P C R$ reproduce una respuesta fisiológica y perceptual similar a la respuesta en VC.

Descriptores: consumo de oxígeno; frecuencia cardíaca; ácido láctico; ejercicio.

\section{INTRODUÇÃO}

Dentre os domínios de intensidade do exercício (ex:: moderado, pesado e severo), o exercício pesado é caracterizado pela maior intensidade do exercício que não está associado ao acúmulo de metabólitos, sendo a perturbação da homeostase muscular e sanguínea por acidose um evento fisiológico associados ao exercício acima deste domínio 1,2 . Tradicionalmente, esse limite é demarcado pela inclinação da relação hiperbólica entre intensidade do esforço e sua tolerância (tempo limite, $t_{\text {Lim }}$ ): a velocidade crítica (VC), ou potência crítica $(P C)^{1}$. No entanto, os procedimentos de determinação de VC (ou PC) têm sido descritos por diferentes protocolos de exercício, com duração entre dois a quinze minutos, e ajustes matemáticos lineares e não-lineares que demandam respostas fisiológicas variando entre 18 $24 \%{ }^{3,4}$ e, assim, comprometem a precisão da demarcação do limite superior do domínio pesado 5 . Essa limitação metodológica conduz à investigação de outros parâmetros, com elevado potencial teórico para representar o domínio fisiológico caracterizado pelo exercício em VC (ou PC). O Ponto de compensação respiratória (PCR) é um desses parâmetros com melhor respaldo teórico, pois caracteriza-se pela intensidade metabólica, durante um teste incremental máximo, em que os mecanismos de controle do equilíbrio ácido-base perdem a capacidade de tamponar a produção de ânions (principalmente hidrogênio, $\mathrm{H}^{+}$) associada à ativação contínua e crescente do metabolismo glicolítico anaeróbio para atender à demanda energética ${ }^{6-8}$. As principais respostas gasosas observadas ao nível pulmonar, que decorrem do acúmulo de metabólitos durante o exercício acima de PCR são: (a) aumento desproporcional da ventilação $\left(\dot{V}_{\mathrm{E}}\right)$, que ocorre independente da produção de dióxido de carbono $\left(\dot{\mathrm{V}} \mathrm{CO}_{2}\right)$, concomitantemente, à (b) redução na pressão expiratória de $\mathrm{CO}_{2}\left(\mathrm{P}_{\mathrm{ET}} \mathrm{CO}_{2}\right)$ e aumento na pressão inspiratória de $\mathrm{O}_{2}\left(\mathrm{P}_{\mathrm{ET}} \mathrm{O}_{2}\right)$, representando a tendência de falência dos mecanismos de tamponamento e do consumo muscular de $\mathrm{O}_{2}^{9-11}$.

A representatividade de $P C R$, em relação ao comportamento fisiológico observado em VC (ou PC), é descrita pela comparação da taxa metabólica relativa ao $\dot{\mathrm{V}}_{2}$ max que ambas tendem a demarcar em seus contextos de avaliação ${ }^{12}$; ou ainda, pelas amplitudes e tempos de respostas do $\dot{\mathrm{VO}}_{2}$ frente ao exercício de fase constante ao redor de $P C R^{13}$. Mas a comparação direta do perfil fisiológico, em resposta ao exercício de fase constante em ambas as intensidades (PCR eVC) ainda não foi descrito. Essa informação descreveria, ou não, a tendência de similaridade na magnitude das repostas cardiorrespiratória e metabólica, pressupondo assim paridade nas respostas centrais e periféricas que, de acordo com Murias, Kowalchuk ${ }^{14}$ e Daussin, Zoll ${ }^{15}$, são determinantes taxa oxidativa e da tolerância ao exercício nesta zona de intensidade.

Dessa forma, o domínio do exercício parametrizado pela resposta fisiológica na VC tem sido comparado à outros índices limítrofes do exercício sustentado por análises pontuais, em diferentes condições de exercício, que não permitem descartar a casualidade. Tendo por intenção contribuir com informações sobre a taxa de ativação de parâmetros fisiológicos em resposta ao exercício em VC e PCR, o presente estudo investigou a hipótese de não haver diferenças no pico da demanda do $\dot{V}_{2}$, frequência cardíaca (FC) e concentração sanguínea de lactato ([La]) entre às transições repouso-exercício realizadas VC e PCR. Outra intenção deste estudo foi a descrição do esforço percebido (PSE) em ambas as intensidades, com o propósito de legitimar as semelhanças pela informação perceptual. Espera-se que a intensidade do exercício em VC e PCR seja classificada pela PSE em patamares atribuídos à outros índices do esforço tolerável em alta intensidade (ex:: PC e Limiar Anaeróbio por resposta lactacidêmica).

\section{MATERIAL E MÉTODOS}

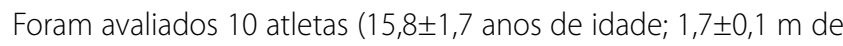
estatura; e 57,1 $\pm 12,4 \mathrm{~kg}$ de peso corporal). Os participantes foram previamente instruídos sobre os procedimentos de avaliação, e todos assinaram o Termo de Consentimento Livre e Esclarecido. Na ocasião do estudo, os participantes apresentavam experiência de dois anos e volu-

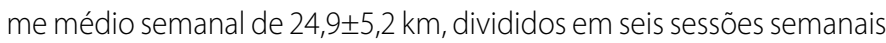
de treinamentos, com distribuição da intensidade em 34,2 $\pm 23,0 \%$ na

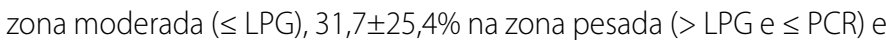
$34,2 \pm 19,5 \%$ na zona severa (> PCR). O presente estudo teve aprovação do Comitê de Ética da Faculdade de Ciências - UNESP, sob o registro CAAE: 02589012.3.0000.5398.

\section{Delineamento experimental}

Os participantes foram submetidos a três diferentes protocolos de testes. O primeiro protocolo consistiu na avaliação da aptidão aeróbia, empregando um teste progressivo (tipo rampa) para determinação do limiar de permuta gasosa (LPG), ponto de compensação respiratória (PCR) e consumo máximo de oxigênio $\left(\mathrm{V}_{2 \text { max }}\right)$, bem como a intensidade de corrida correspondente ( $\mathrm{VLPG}, \mathrm{VPCR}$ e $v \dot{V}^{2} \mathrm{Imax}_{\text {max }}$ ). Após $24 \mathrm{~h}$ iniciaram-se os testes de velocidade constante a $85 \%, 90 \%$ e $110 \%$ v $\dot{V}_{2 \max }$ para predição da VC. Os participantes foram instruídos, bem como encorajados, a conduzir seu esforço ao limite da tolerância em cada velocidade de corrida. Foi respeitado um intervalo mínimo de $24 \mathrm{~h}$ e máximo de $48 \mathrm{~h}$ entre cada esforço. $\mathrm{O}$ último protocolo consistiu em realizar duas transições repouso-exercício por sete minutos em VC e vPCR. As transições foram executadas e repetidas aleatoriamente, com intervalo mínimo de duas horas, sendo realizadas duas por dia ${ }^{16}$. No total, os participantes realizaram oito testes em até $2-3$ semanas. Todos os testes foram realizados em uma esteira motorizada (HP/Cosmos Pulsar, Nussdorf-Traunstein, Germany), 
com inclinação mantida em 1,0\%, dentro de um ambiente fechado com temperatura controlada $\left(21-23^{\circ} \mathrm{C}\right)$. Os indivíduos foram instruídos a evitar treinos exaustivos, bebidas alcoólicas e cafeínadas no dia anterior a avaliação, bem como comparecer alimentados e hidratados.

O teste progressivo foi realizado em esteira motorizada, com inclinação mantida em $1,0 \%{ }^{17}$ ao longo do protocolo. A velocidade ini-

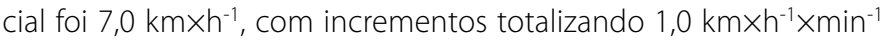

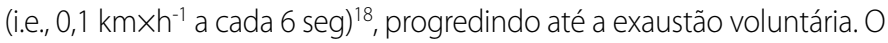
$\dot{\mathrm{V}} \mathrm{O}_{2}$ foi mensurado respiração-a-respiração durante todo o teste, a partir de uma unidade CPET (QuarkPFTergo, Cosmed, Roma, Itália). A calibração do software de análise das concentrações de $\mathrm{O}_{2} \mathrm{e} \mathrm{CO}_{2}$ foi realizada antes de cada teste, conforme instruções do fabricante. As amostragem do $\dot{\mathrm{VO}}_{2}$ foi suavizada por filtro de três seg e obtido médias a cada intervalo de nove seg. A frequência cardíaca (FC) e a percepção subjetiva de esforço (PSE) foram registrados ao final de cada minuto e ao final do teste, sendo neste último instante considerados "FC $C_{\max }$ e PSE max $_{\text {max }}$. A PSE foi analisada empregando a escala de 15 pontos $\left(6\right.$ - 20) ${ }^{19}$ e a FC foi registrada batimento-a-batimento por frequencímetro (Polar ${ }^{\circledR}$ S810i, Kempele, Finland). A concentração de lactato sanguíneo ([La]) foi analisada no primeiro minuto após o término do teste progressivo e definido como "[ $\left.\mathrm{La}_{\max }\right]$ ". Para a análise da concentração de lactato, uma amostra de $25 \mu \mathrm{l}$ de sangue arterial foi retirada do lóbulo da orelha. Essa amostra foi imediatamente acondicionada em tubo Eppendorf, contendo 50 $\mu$ l de fluoreto de sódio (NaF) a 1\%. Em seguida, a amostra foi analisada, ou congelada para ser analisada posteriormente. A análise da concentração de lactato foi realizada pelo método enzimático (YSL 2500STAT, Yellow Spring, Colorado).

LPG e PCR foram determinados conforme as recomendações de Beaver et al ${ }^{6}$ e Caiozzo et al. ${ }^{20}$, por observação visual das respostas de $\dot{\mathrm{V}}_{\mathrm{E}} \times \dot{\mathrm{V}} \mathrm{CO}_{2}{ }^{-1}, \dot{\mathrm{V}}_{\mathrm{E}} \times \dot{\mathrm{VO}}_{2}{ }^{-1}, \mathrm{P}_{\mathrm{ET}} \mathrm{CO}_{2}$ e $\mathrm{P}_{\mathrm{ET}} \mathrm{O}_{2}$. Os critérios para determinar LPG foram: aumento na curva da relação $\dot{\mathrm{V}}_{\mathrm{E}} \times \dot{\mathrm{V}}_{2}{ }^{-1}$ e na $\mathrm{P}_{\mathrm{ET}} \mathrm{O}_{2}$, sem alteração da relação $\dot{V}_{E} \times \dot{V} C_{2}{ }^{-1}$ e na $P_{E T} C_{2}$; e para PCR: aumento concomitante e sustentado dos parâmetros $\dot{V}_{\mathrm{E}} \times \dot{\mathrm{VO}}_{2}{ }^{-1} \mathrm{e}_{\mathrm{V}} \times \dot{\mathrm{V}} \mathrm{CO}_{2}{ }^{-1}$, concomitante à diminuição da $\mathrm{P}_{\mathrm{ET}} \mathrm{CO}_{2}$. $\mathrm{O}_{\mathrm{V}} \mathrm{O}_{2 \max }$ foi considerado o maior valor registrado e a $\vee \dot{V}_{2 \text { max }}$ foi considerada a velocidade de corrida que projetou o $\dot{\mathrm{VO}}_{2}$ ao máximo. Também foram adotados critérios secundários para confirmar o esforço máximo nos estágios finais do protocolo: quociente respiratório $(\mathrm{QR})>1$, 1; frequência cardíaca ( $F C>95 \% \mathrm{FC}_{\max }$ prevista pela idade; e concentração de lactato sanguíneo ([La]) $\geq 8 \mathrm{mmol} \times \mathrm{L}^{-1(21}$. As análises de determinação de LPG, PCR e $\dot{V} O_{2 \text { max }}$ foram realizadas por dois ou três pesquisadores experientes, de forma independente.

Os esforços preditivos de VC foram realizados à 85\%, $90 \%$ ou $110 \% \mathrm{VV}_{2 \max }$. Cada esforço foi realizado de forma aleatória, com intervalos mínimos de $24 \mathrm{~h}$. Antes de cada esforço, foi realizado um aquecimento de 5 min em intensidade correspondente à $50-60 \%$ v $\mathrm{VO}_{2 \text { max }}$ seguido de 5 min de intervalo. O tempo-limite $\left(t_{\text {Lim }}\right)$ foi considerado a tolerância máxima ao exercício em cada \% $\mathrm{vV}_{2 \max }$ e expressado em seg. Os valores individuais de velocidade e $t_{\text {Lim }}$ foram ajustados pelo modelo velocidade $v$ s. inverso do tempo ( $v$ - $t_{\text {Lim }}{ }^{-1}$, Equação 1), estimado VC e a D' (equivalente ao W' do modelo trabalho-tempo limite) ${ }^{12,22}$.

$$
\mathrm{v}=\mathrm{D}^{\prime} \mathrm{x} \frac{1}{(\mathrm{t})}+\mathrm{VC}
$$

onde: $v$ = velocidade de corrida; $\mathrm{D}^{\prime}=$ equivalente ao $\mathrm{W}^{\prime} ; t=$ é o tempo de exercício e $V C$ = é a velocidade crítica.

Os participantes realizaram duas transições em VC e vPCR, cada uma com 7 min de duração. No máximo duas transições foram realizadas em cada dia, com intervalo mínimo de $2 \mathrm{~h}$, sendo a ordem de execução sorteada. Outras duas transições, foram realizadas com $24 \mathrm{~h}$ de intervalo, repetindo-se o mesmo procedimento. Antes de cada teste foi realizado um aquecimento de 5 min em intensidade correspondente a 50 - $60 \%$ v $\mathrm{V}_{2 \text { max }}$ seguido de 5 min de intervalo.

O comportamento fisiológico foi analisado pela resposta do $\dot{\mathrm{V}} \mathrm{O}_{2}, \mathrm{FC}$ e [La], enquanto a resposta perceptual foi analisada pela PSE (escala 6 - 20). O $\mathrm{V}_{2}$ e a FC foram obtidos durante todo o protocolo de exercício em VC e VPCR, sendo registrados respiração-a-respiração e batimento-a-batimento, respectivamente. A PSE foi obtida ao final de cada minuto e o sangue amostrado apenas ao final das transições. Os valores mais elevados de $\dot{V}_{2}$, FC, PSE e [La] foram considerados resposta de pico (ex:: $\dot{V} O_{2 \text { pico, }}$ FC $_{\text {pico, }}$ PSE $_{\text {pico }}$ ) e finais ([La $]_{\text {fim }}$ ) durante ambas transições.

\section{Análise estatística}

Os dados foram expressos em médiatDP. A normalidade dos dados foi verificada pelo teste de Shapiro-Wilk. Os parâmetros fisiológicos $\left(\mathrm{FC}_{\text {picor }}[\mathrm{La}]_{\text {Fim }}\right.$ e $\dot{\mathrm{V}} \mathrm{O}_{2 \text { pico }}$ ) e perceptuais $\left(\mathrm{PSE}_{\text {pico }}\right)$ foram analisados em termos relativos aos valores máximos destes mesmos índices observados no teste progressivo. As diferenças entre as médias de resposta destes índices em VC vs. vPCR foram averiguadas pelo Teste de Mann-Whitney (U). As análises de variância e concordância entre as respostas destes índices em VC vs. VPCR foram realizadas pelo coeficiente de dispersão $\left(R^{2}\right)$ e por Bland-Altman. O poder amostral frente ao coeficiente de correlação linear foi determinado pela equação:

$$
Z_{1-\beta}=\sqrt{ } n-3 \frac{1}{2} \operatorname{Ln}\left(\frac{1+r}{1-r}\right)-Z_{1-\alpha / 2}
$$

onde $Z_{1-\beta}$ fornece o coeficiente para a determinação do poder amostral pela distribuição normal bicaudal de seu valor e " $r$ " é o coeficiente linear ${ }^{23}$. Em todas as análises, o nível de significância foi fixado em $P \leq 0,05$.

\section{RESULTADOS}

Os valores obtidos durante o teste incremental foram: $\dot{\mathrm{V}}_{2 \max }=$ $56,1 \pm 5,5 \mathrm{ml} \mathrm{kg}^{-1} \times \mathrm{min}^{-1} ; v^{\prime} \mathrm{VO}_{2 \max }=16,5 \pm 1,7{\mathrm{~km} \times \mathrm{h}^{-1} ;} \mathrm{FC}_{\max }=202 \pm 12$ bpm; $P S E_{\max }=19,4 \pm 1,3$; e $[\mathrm{La}]=12,7 \pm 3,1 \mathrm{mmol} \times \mathrm{L}^{-1}$. As referências de

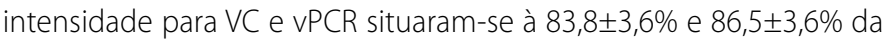
$\vee \mathrm{V}_{2 \text { max }}$, respectivamente (Figura 1). A Figura 2 apresenta os valores para as respostas das variáveis $\mathrm{PSE}_{\text {pico, }}, \mathrm{FC}_{\text {pico, }}, \dot{\mathrm{V}} \mathrm{O}_{2 \text { pico }}$ e $[\mathrm{La}]_{\text {Fim }}$ durante as transições em VC e vPCR. Os valores (média土DP) estão descritos em termos relativos às respostas máximas das respectivas variáveis obtidas no teste progressivo. Não foram observadas diferenças entre as respostas em VC e VPCR para PSE $E_{\text {pico }}(U=46,0 ; P=0,761 ; Z=-0,304) ; F C_{\text {pico }}(U=28,0 ; P=0,096$; $Z=-1,664) ;[L a]_{\text {Fim }}=(U=28,5 ; P=0,104 ; Z=-1,627) ; e \dot{V O}_{2 \text { pico }}=(U=38,0$; $P=0,364 ; Z=-0,907)$.

Os coeficientes de explicação da variância nas respostas de PSE $_{\text {pico' }}$ $\mathrm{FC}_{\text {pico, }}[\mathrm{La}]_{\text {Fim }}$ e $\dot{\mathrm{V}} \mathrm{O}_{\text {2pico }}$ durante o exercício em VPCR para aquele realizado em VC estão apresentados nas Figuras 3A, 3B, 3C e 3D. O poder amostral $(n=10)$ para o efeito da similaridade, com baixa probabilidade de ocorrência de erro tipo II, entre as respostas de $P S E_{\text {pico }}\left(Z_{\beta-1}=1,29\right.$; valor de $\left.Z=0,90\right)$, $F C_{\text {pico }}\left(Z_{\beta-1}=-0,20\right.$; valor de $\left.Z=0,42\right)$, $[\mathrm{La}]_{\text {Fim }}\left(Z_{\beta-1}=0,67\right.$; valor de $\left.Z=0,75\right)$, e $\dot{V} O_{2 \text { pico }}\left(Z_{\beta-1}=1,07\right.$; valor de $\left.Z=0,86\right)$ mostram-se satisfatórios $\left(Z_{a-1}=1,96\right.$ e poder de $\left.80 \%\right)$ apenas para as variáveis PSE e VO $\mathrm{V}_{2}$. Os valores do coeficiente de correlação linear, aplicados na equação 2, mostram efeitos significativos entre VC vs. vPCR para as variáveis [La] Fim $(r=0,76 ; P=0,011)$, PSE $_{\text {pico }}(r=0,84 ; P<0,01)$ e $\dot{V}_{2 \text { pico }}(r=0,82$; $P<0,01)$, mas não para $F C_{\text {pico }}(r=0,58 ; P=0,08)$. No entanto, a análise Bland-Altman (Figura 4) revela que há concordância entre as respostas de pico de PSE, FC e VंO ${ }_{2}$ e $[\mathrm{La}]_{\text {Fim }}$ durante o exercício em VC e VPCR.

\section{DISCUSSÃO}

O presente estudo não encontrou diferenças entre a magnitude das respostas dos índices fisiológicos e perceptuais analisados durante as 
transições em VC e vPCR. Assim, frente as respostas de pico de $\mathrm{FC}, \dot{\mathrm{V}}_{2} \mathrm{e}$ PSE e final de [La], ao executar e repetir o exercício em VC e vPCR, pode-se confirmar a hipótese de similaridade no patamar de esforço caracterizado por ambas as intensidades. Portanto, se à VC é atribuído o papel de

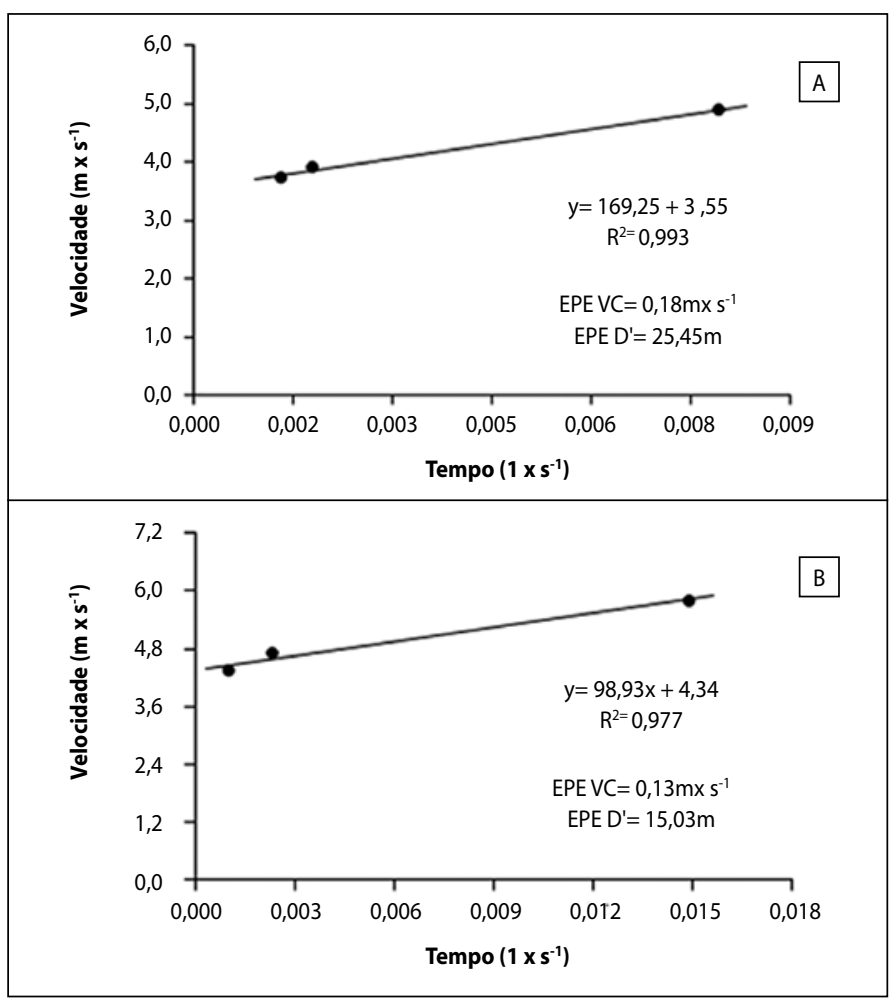

Figura 1. Exemplo da determinação da velocidade crítica (VC) em dois participantes. O EPE médio associado à VC foi $0,11 \pm 0,06 \mathrm{~m} \cdot \mathrm{s}^{-1}$. delimitar a intensidade máxima do exercício sustentada sem que a fadiga ocorra pelos eventos da acidose metabólica (ex:: domínio pesado) ${ }^{24}$, então há uma tendência de PCR em representar também essa mesma função.

As respostas fisiológicas e perceptuais ao exercício em VC tendem a ser similares entre os métodos de determinação ${ }^{4}$. Bull et al. ${ }^{4}$ analisaram a frequência cardíaca (FC) e a percepção subjetiva do esforço (PSE) durante dois esforços até a exaustão e/ou 60 min de duração. Dentre aqueles que completaram a atividade, $01^{\circ}$ esforço $\left(F C=93 \pm 5 \% F C_{\text {max }} P S E=19 \pm 1\right)$ não diferiu do $2^{\circ}$ esforço $\left(F C=91 \pm 5 \% F C_{\text {maxi }}\right.$ PSE $\left.=17 \pm 3\right)$ durante o exercício em VC pelo método não-linear de 3 parâmetros. Housh at al. ${ }^{3}$ também observaram similaridades nas respostas do $\dot{\mathrm{VO}}_{2}$, $\mathrm{FC}$ e lactato sanguíneo durante os exercícios em VC determinado por diferentes métodos. Esses autores descreveram as respostas pelos métodos linear da distância total $\left(\mathrm{d}-\mathrm{t}_{\text {Lim }}\right)\left(95 \% \dot{\mathrm{VO}}_{2 \text { maxi }} 97 \% \mathrm{FC}_{\text {max }} ; 74 \%[\mathrm{La}]_{\text {max }}\right)$, para linear-v $\left(\mathrm{V}-\mathrm{t}_{\text {Lim }}\right)\left(96 \% \mathrm{VO}_{2 \text { maxi }}\right.$

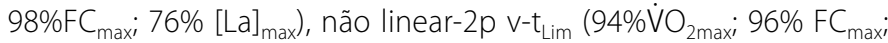
$\left.71 \%[L a]_{\text {max }}\right)$, não linear-3p v-t $L_{\text {Lim }}\left(89 \% \mathrm{VO}_{2 \text { max }} ; 93 \% \mathrm{FC}_{\text {maxi }} ; 63 \%[L a]_{\text {max }}\right) \mathrm{e}$

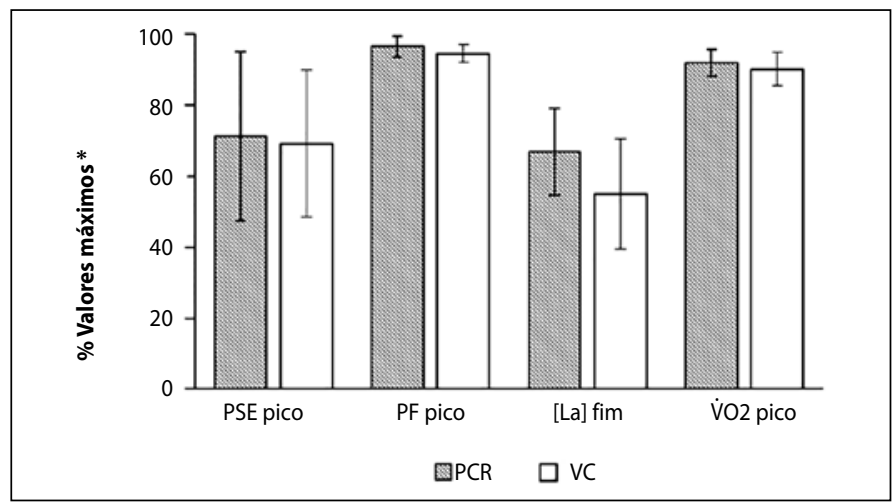

Figura 2. Média \pm DP para as respostas de $\mathrm{PSE}_{\text {picor }} \mathrm{FC}_{\text {picor }}[\mathrm{La}]_{\text {Fim }}$ e $\dot{\mathrm{V}}_{2 \text { pico. }}$. Obs.: valores estão descritos em termos relativos às respectivas respostas máximas no teste progressivo.

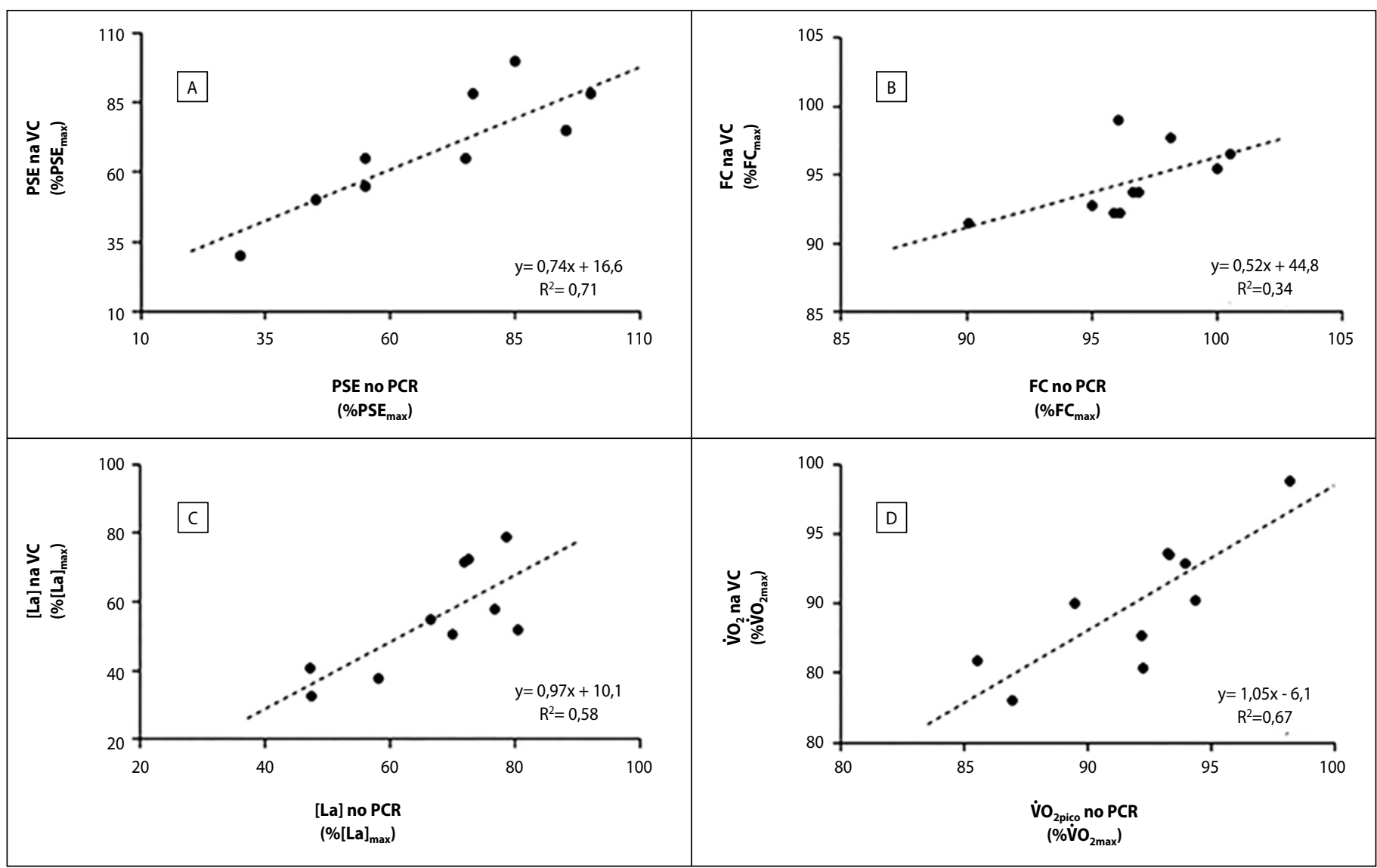

Figura 3. Relação entre as variâncias nas respostas de pico de PSE (A), FC (B), e $\dot{V}_{2}$ (D) e final de [La] em VC e vPCR. Ver texto para detalhes sobre o poder amostral do efeito de similaridade. 


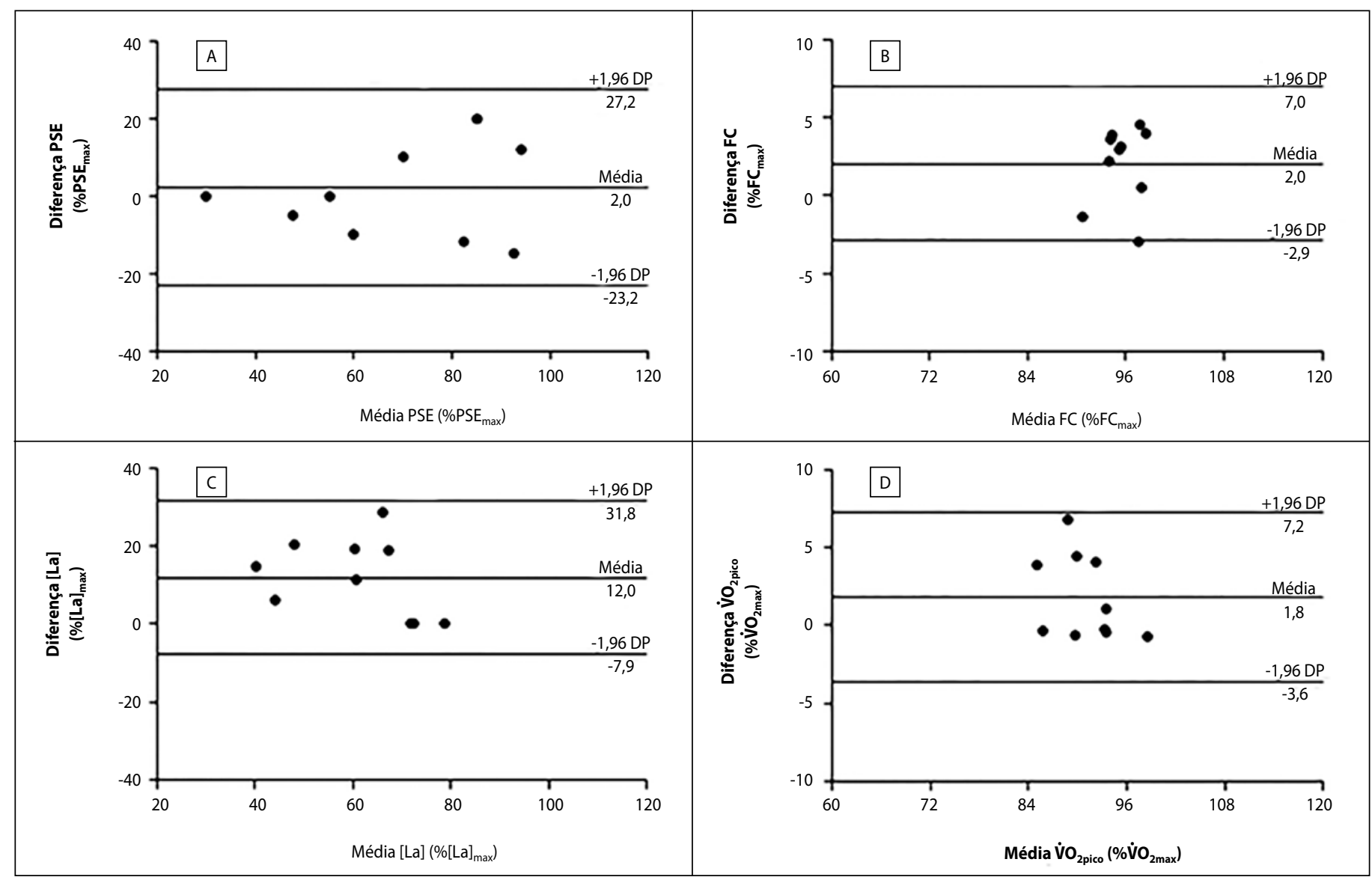

Figura 4. Análise de Bland-Altman para a concordância entre as respostas de pico de PSE (A), FC (B), e $\dot{V} \mathrm{O}_{2}$ (D) e final de [La] (C) em VC e vPCR.

exponencial (105\% $\dot{\mathrm{V}} \mathrm{O}_{2 \max i}$ 104\% $\left.\mathrm{FC}_{\text {maxi }} ; 103 \%[\mathrm{La}]_{\max }\right)$. Os valores do presente estudo para as respostas destes mesmos parâmetros em VC e PCR diferenciam-se apenas dos valores em respostas à intensidade parametrizada pelo método exponencial. Dessa forma, as diferenças entre as respostas fisiológicas em VC e vPCR, quando houverem, não tendem a ser superior aquelas demonstradas durante o exercício em VC determinada pelos métodos comumente aplicados: $\left(d-t_{\text {Lim }}\right.$, linear $v-t_{\text {Lim }}$, não linear- $2 p v-t_{\text {Lim }}$ e não linear-3p v- $\left.t_{\text {Lim }}\right)$.

As comparações diretas entre VC (ou PC) e vPCR corroboram essa similaridade de intensidade de esforço e de ativação metabólica entre ambos. Dekerle et al. ${ }^{25}$ foram pioneiros em demonstrar essa tendência de similaridade, observando que PC $\left(278 \pm 22 \mathrm{~W} ; 85,4 \pm 4,8 \% \dot{V}_{2 \max }\right)$ e iPCR (286 $\left.\pm 28 \mathrm{~W} ; 85,3 \pm 5,6 \% \dot{\mathrm{V}}_{2 \max }\right)$ não diferiram entre si $(\mathrm{p}=0.96)$ no ciclismo, embora ambos sejam intensidades maiores $(p<0,05)$ que MFEL $\left(239 \pm 21 \mathrm{~W}_{;} 74,3 \pm 4,0 \dot{V}_{2 \max }\right)$ e LV $\left(159 \pm 23 \mathrm{~W} ; 52,9 \pm 6,9 \% \dot{\mathrm{V}} \mathrm{O}_{2 \max }\right)$. Recentemente, a similaridade entre VC e vPCR também foi examinada por Broxterman et al. ${ }^{12}$, que não observaram diferenças entre VC e vPCR ao serem comparados pela velocidade de corrida $\left(11,5 \pm 2,3 \mathrm{~km} \times \mathrm{h}^{-1} \mathrm{vs}\right.$.

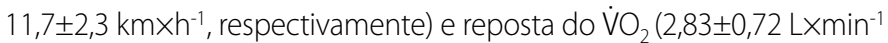

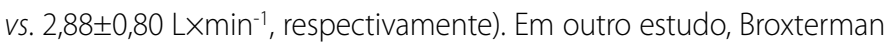
et al. ${ }^{26}$ analisaram o efeito da cadência sobre a determinação de PC e PCR e verificaram que iPCR é alterada significativamente quando determinada a 100 rpm e a 60 rpm $\left(61,8 \pm 10,2 \%\right.$ vs. 68,6 $\pm 8,4 \%$ iV ${ }_{2 \text { max }}$ respectivamente), contudo igual alteração foi observada na determinação de PC (60,3 $\pm 8,8 \%$ vs. $65,9 \pm 11,1 \% \mathrm{iVO}_{2 \text { max }}$ respectivamente à $100 \mathrm{rpm}$ e à $\left.60 \mathrm{rpm}\right)$, sendo novamente impossível distinguir PC de iPCR seja a 100 rpm ou a 60 rpm. Essa similaridade não se limitou à intensidade, como também à resposta do $\dot{\mathrm{VO}}_{2}$ a $100 \mathrm{rpm}\left(72,0 \pm 4,0 \%\right.$ vs. $\left.73,0 \pm 9,0 \% \dot{\mathrm{VO}}_{2 \max }\right)$ ou a $60 \mathrm{rpm}(79,0 \pm 14,0 \%$ vs. $78,0 \pm 9,0 \% \dot{V_{0}}{ }_{2 \text { max }}$ ), respectivamente para PC de iPCR. Por fim, mesmo com a alteração de protocolo (teste all-out em cicloergômetro), Bergstrom et al. ${ }^{27}$ concluíram que não há diferenças entre PC $\left(187 \pm 47 \mathrm{~W} ; 83 \pm 6 \% \dot{\mathrm{VO}}_{2 \max }\right)$ e iPCR (190 $\pm 49 \mathrm{~W} ; 84 \pm 6 \% \dot{V}_{2 \text { max }}$ ). Essas similaridades conduziram os autores a postular que caso existam diferenças entre PC e iPCR estas são atribuídas ao nível de treinamento entre os participantes analisados, e que a variabilidade na respostas fisiológica pode estar associado ao erro na estimativa de PC e iPCR, ou ainda aos métodos e instrumentos de determinação dos parâmetros fisiológicos analisados.

A PSE é considerada uma variável psicológica capaz de indexar a intensidade do exercício pela informação perceptual, integrando os níveis de ativação de diferentes sistemas (muscular, cardiorrespiratório e neural) que sustentam o esforço físico ${ }^{19}$. Enquanto indexador da capacidade de tolerância ao exercício prolongado, a PSE tem evidenciado significativa correspondência com índices fisiológicos do exercício aeróbio de alta intensidade ${ }^{28}$. Por exemplo, Bergstrom et al. ${ }^{29}$ verificaram que a estimativa do $\dot{\mathrm{V}} \mathrm{O}_{2}\left(81 \% \dot{\mathrm{V}}_{2 \text { pico }}\right)$, carga $\left(78 \% \mathrm{iV}_{2 \text { pico }}\right)$ e $\mathrm{PSE}^{15}$ correspondente ao limiar de esforço percebido não difere da estimativa destes mesmos para PCR (83\% ن VO $_{2 \text { pico, }} 81 \%$ iVंO ${ }_{2 \text { pico }}$ e PSE $\left.=15,4\right)$, porém são maiores que aqueles observados para LPG $\left(74 \% \dot{V}_{2 \text { pico, }} 70 \% \mathrm{iVO}_{2 \text { pico }}\right.$ e PSE $\left.=14\right)$. Ao analisar a resposta da PSE durante o exercício em intensidade correspondente à potência crítica (PC) $\left(82,5 \%\right.$ VंO $\left._{2 \text { max }}\right)$, Soares-Caldeira et al..$^{30}$ observaram que o valor de PSE progride até o valor máximo no momento da exaustão. Para esses autores, a PSE foi o único parâmetro que esboçou essa tendência, quando comparado às resposta de elevação da $F C\left(93,3 \% \mathrm{FC}_{\max }\right)$ e [La] $\left(81,8 \%[\mathrm{La}]_{\max }\right)$. Porém, entre 5 a 10 min de exercício, a PSE esteve em

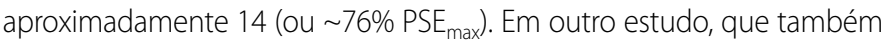
analisou a resposta da PSE na PC, Bergstrom et al. ${ }^{27}$ observaram a mesma tendência de progressão durante o exercício contínuo até a exaustão, porém os valore entre o terceiro e o quinto minuto de atividades foram adotados pelos autores como referência para a resposta de parâmetros fisiológicos $\left(\dot{\mathrm{V}} \mathrm{O}_{2} \sim 86 \% \dot{\mathrm{V}}_{2 \text { pico }}\right.$ e FC $290 \%$ FCpico) e perceptual (PSE $=15,6$, ou $\sim 80 \%$ $\mathrm{PSE}_{\text {max }}$ ). No estudo de Marcora e Staiano ${ }^{28}$, a resposta da PSE e de outros 
índices fisiológicos foi analisada durante um teste constante até a exaustão, em intensidade correspondente à $80 \% \dot{\mathrm{V}}_{2 \text { pico. }}$. Também observaram ao oitavo minuto de exercício valores para a PSE, FC e [La] que atingiram, respectivamente, $\sim 77 \%, \sim 95 \%$ e $\sim 70 \%$ da resposta ao final do exercício. Assim, ao comparar os valores apresentados na Figura 2 do presente estudo com os valores mencionados acima, verifica-se que houve similaridades nas respostas em VC e PCR. Portanto, pode-se afirmar que os contextos de intensidade do esforço caracterizados pelo exercício em VC e PCR não diferem daqueles analisados na literatura e que, quando comparados por parâmetros perceptuais e fisiológicos, tampouco diferem entre si.

Particularmente, essa afirmação corrobora a suposição de Marcora e Staiano ${ }^{28}$ sobre o papel da PSE em indexar a tolerância ao esforço aeróbio de alta intensidade, juntamente com outros fatores do engajamento no exercício, como o potencial motivacional. Foi preconizado por esses autores que o valor de PSE em um momento comum do exercício de alta intensidade tende a influenciar de forma negativa o tempo de exaustão, pressupondo a existência de modelo psicobiológico de estimativa do desempenho. Portanto, o presente estudo permite especular que não há diferenças na percepção do esforço ao realizar o exercício em VC e PCR e que, além disto, há uma provável tendência de similaridade na disposição à tolerância nestas duas intensidades. Todavia, essa última especulação é limitada pelo fato do presente estudo não ter analisado o tempo-limite do exercício em VC e PCR.

Uma possivel limitação deste estudo é o protocolo utilizado para determinar VC, uma vez que sua variabilidade está associada aos protocolos de avaliação (tempo-limite nos esforços preditivos para permitir o alcance do $\dot{V} O_{2 \text { max: }} 3$ a 15 min, à 90\%, 100\% e 110\% $\dot{V}_{2 \text { max }}$ ) e tipos de ajuste (linear e não-linear) $)^{5}$. Todavia, no presente estudo, os tempos-limites (Figura 1) situaram-se entre $\sim 116 \mathrm{~s}$ (primeira preditiva) e $721 \mathrm{~s}$ (terceira preditiva), que estão em conformidade com as sugestões de Hill et al. ${ }^{31}$ e Greco et al. ${ }^{32}$ para as preditivas de VC (ou PC). Assim, apesar da possibilidade de VC ter sido superestimada, os procedimentos atenderam aos critérios estabelecidos na literatura e apresentaram valores baixos de EPE (Figura 1).

\section{CONCLUSÃO}

A contribuição do presente estudo é relevante ao demonstrar que há uma intensidade fisiológica durante o exercício progressivo, limítrofe da regulação respiratória para compensar a manifestação da acidose metabólica, capaz de fornecer um parâmetro (ex. PCR) delimitador do limite superior domínio pesado do exercício, frente às similaridades fisiológicas e perceptuais com o exercício em VC (ou PC). Apesar da amostragem ( $n=10)$ apresentar um poder estatístico de 86\% e 90\%, respectivamente para a similaridade da variância nas resposta do $\dot{V}_{2}$ e PSE durante o exercício em PCR e VC, é importantante ressaltar que a efetividade desta comparação e interpretação deste resultado está associado às particularidades da população analisada. Assim, restringindo uma possível generalização à população com faixa etária diferente daquela analisada no presente estudo.

\section{AGRADECIMENTOS}

Os autores agradecem ao Conselho Nacional de Desenvolvimento Científico e Tecnológico (CNPq) o apoio financeiro ao projeto n'479262/2013-6.

Todos os autores declararam não haver qualquer potencial conflito de interesses referente a este artigo.

CONTRIBUIÇÕES DOS AUTORES: Cada autor contribuiu individual e significativamente para o desenvolvimento do manuscrito. DMPF (0000-0003-3975-9260)*, e DAM (0000-0003-1088-0040)* foram os responsáveis pela idealização da proposta, coleta de dados, apresentação dos resultados e discussão literária dos resultados observados BSD (0000-0003-0775-1889)*, acompanhou o tratamento dos dados e contribuiu com a revisão do manuscrito e da base conceitual do estudo. RACA (0000-0002-6198-0423), participou do processo de coleta dos dados, armazenamento e tratamento do dados, bem como da revisão conceitual final. ${ }^{*}$ ORCID (Open Researcher and Contributor ID).

\section{REFERÊNCIAS}

1. Jones AM, Vanhatalo A, Burnley M, Morton RH, Poole DC. Critical power: implications for determination of V O2max and exercise tolerance. Med Sci Sports Exerc. 2010;42(10):1876-90

2. Murgatroyd SR, Ferguson C, Ward SA, Whipp BJ, Rossiter HB. Pulmonary O2 uptake kinetics as a determinant of high-intensity exercise tolerance in humans. J Applied Physiol. 2011;110(6):1598-606.

3. Housh TJ, Cramer JT, Bull AJ, Johnson GO, Housh DJ. The effect of mathematical modeling on critical velocity. Eur J Appl Physiol. 2001;84(5):469-75

4. Bull AJ, Housh TJ, Johnson GO, Perry SR. Effect of mathematical modeling on the estimation of critical power. Med Sci Sports Exerc.. 2000;32(2):526-30.

5. Bull AJ, Housh TJ, Johnson GO, Rana SR. Physiological responses at five estimates of critical velocity. Eur J Appl Physiol.. 2008;102(6):711-20.

6. Beaver WL, Wasserman K, Whipp BJ. A new method for detecting anaerobic threshold by gas exchange. J Appl Physiol. 1986;60(6):2020-7.

7. Wasserman K, Casaburi, R. Acid-base regulation during exercise in humans. (405-448). In: Whipp BJ, Wasserman. Pulmonary physiology and pathophysiology of exercise. New York: Dekker. 1991. p. 605.

8. Dekerle J, Brickley G, Alberty M, Pelayo P. Characterising the slope of the distance-time relationship in swimming. J Sci Med Sport. 2010;13(3):365-70.

9. Whipp BJ, Ward, SA. Coupling of ventilation to pulmonary gas exchange during exercise. (271-307). In:Whipp BJ, Wasserman. Pulmonary physiology and pathophysiology of exercise. New York: Dekker. 1991, p. 605.

10. Whipp BJ. Physiological mechanisms dissociating pulmonary $\mathrm{CO} 2$ and $\mathrm{O} 2$ exchange dynamics during exercise in humans. Exp Physiol. 2007;92(2):347-55.

11. Johnson RL, Heigenhauser GJF, Hsia CCW, Jones NL, Wagner PD. Determinants of gas exchange and acid-base balance during exercise. (415-584). In: Rowell LB, Shepherd JT. Exercise: regulation and integration of multiple systems. New York: Oxford University Press. 1996. p. 1210.

12. Broxterman RM, Ade CJ, Craig JC, Wilcox SL, Schlup SJ, Barstow TJ. The relationship between critical speed and the respiratory compensation point: coincidence or equivalence. Eur J Sport Sci.. 2015;15(7):631-9.

13. Pessoa Filho DM, Alves FB, Reis JF Greco CC, Denadai BS. Oxygen uptake kinetics as a determinant of exercise intensity domains. Int J Sports Med. 2012;33(10):855.

14. Murias JM, Kowalchuk JM, Paterson DH. Time course and mechanisms of adaptations in cardiorespiratory fitness with endurance training in older and young men. J Appl Physiol. 2010;108(3):621-7.

15. Daussin FN, Zoll J, Dufour SP, Ponsot E, Lonsdorfer-Wolf E, Doutreleau S, Mettauer B, Piquard F, Geny B, Richard R. Effect of interval versus continuous training on cardiorespiratory and mitochondrial functions: relationship to aerobic performance improvements in sedentary subjects. Am J Physiol Regul Integr Comp Physiol. 2008;295(1):R264-72

16. Burnley M, Doust JH, Jones AM. Time required for the restoration of normal heavy exercise VO2 kinetics following prior heavy exercise. J Appl Physiol (1985). 2006;101(5):1320-7.

17. Jones AM, Doust JH. A $1 \%$ treadmill grade most accurately reflects the energetic cost of outdoor running J Sports Sci. 1996;14(4):321-7.

18. Vucetic V Sentija D, Sporis G Trajkovic N, Milanovic Z Comparison of ventilation threshold and heart rate deflection point in fast and standard treadmill test protocols. Acta Clin Croat. 2014;53(2):190-203.

19. Borg GA. Psychophysical bases of perceived exertion. Med Sci Sports Exerc. 1982;14(5):377-81.

20. Caiozzo VJ, Davis JA, Ellis JF, Azus JL, Vandagriff R, Prietto CA, McMaster WC. A comparison of gas exchange indices used to detect the anaerobic threshold. J J Appl Physiol Respir Environ Exerc Physiol. 1982;53(5):1184-9.

21. Poole DC, Wilkerson DP, Jones AM. Validity of criteria for establishing maximal $\mathrm{O} 2$ uptake during ramp exercise tests. Eur J Appl Physiol. 2008;102(4):403-10.

22. Hill DW. The critical power concept. A review. Sports Med. 1993;16(4):237-54.

23. Díaz SP, Fernández SP. Determinación del tamaño muestral para calcular la significación del coeficiente de correlación lineal. Unidad de Epidemiología Clínica y Bioestadística. Complexo Hospitalario Juan Canalejo. A Coruña (España): Cad Aten Primaria. 2002;9:209-11.

24. Jones AM, Grassi B, Christensen PM, Krustrup P, Bangsbo J, Poole DC. Slow component of VO2 kinetics: mechanistic bases and practical applications. Med Sci Sports Exerc.. 2011;43(11):2046-62.

25. Dekerle J, Baron B, Dupont L,Vanvelcenaher J, Pelayo P. Maximal lactate steady state, respiratory compensation threshold and critical power. Eur J Appl Physiol. 2003;89(3-4):281-8.

26. Broxterman RM, Ade CJ, Barker T, Barstow TJ. Influence of pedal cadence on the respiratory compensation point and its relation to critical power. Respir Physiol Neurobiol. 2015;208:1-7.

27. Bergstrom HC, Housh TJ, Zuniga JM, Traylor DA, Lewis RW, Camic CL, Schmidt RJ, Johnson, GO. Responses during exhaustive exercise at critical power determined from the 3-min all-out test. J Sports Sci. 2013;31(5):537-45.

28. Marcora SM, Staiano W. The limit to exercise tolerance in humans: mind over muscle? Eur J Appl Physiol. 2010;109(4):763-70

29. Bergstrom HC, Housh TJ, Zuniga JM, Camic CL, Traylor DA, Schmidt RJ, Johnson GO. Estimated times to exhaustion and power outputs at the gas exchange threshold, physical working capacity at the rating of perceived exertion threshold, and respiratory compensation point. Appl Physiol Nutr Metab.. 2012;37(5):872-9.

30. Soares-Caldeira LF, Okuno NM, Magalhaes Sales M, Campbell CS, Simões HG, Nakamura FY. Similarity in physiological and perceived exertion responses to exercise at continuous and intermittent critical power. Eur J Appl Physiol. 2012;112(5):1637-44

31. Hill DW, Poole DC, Smith JC. The relationship between power and the time to achieve VO2max. Med SC Sports Exerc. 2002;34(4):709-14

32. Greco CC, Carita RA, Dekerle J, Denadai BS. Effect of aerobic training status on both maximal lactate steady state and critical power. Appl Physiol Nutr Metab. 2012;37(4):736-43. 